SHORT REPORT

\title{
Life course measures of socioeconomic position and self reported health at age 50: prospective cohort study
}

\section{Jean Adams, Martin White, Mark S Pearce, Louise Parker}

J Epidemiol Community Health 2004;58:1028-1029. doi: 10.1136/jech.2004.019679

$\mathrm{T}$ here is evidence that premature mortality is predicted by both cumulative ${ }^{1}$ and pathway measures of life course socioeconomic position (SEP). ${ }^{2}$ However, no work to date has investigated the relation between life course SEP and self reported health around age 50 . We assessed the association between self reported limiting longstanding illness (LLSI) at age 50 and both cross sectional and life course measures of SEP.

\section{METHODS AND RESULTS}

The Newcastle thousand families study is a prospective cohort study of all people born in May and June 1947 in Newcastle upon Tyne, UK. ${ }^{3}$ These people have been followed up to age 50 and data are available on SEP at birth (collected contemporaneously), age 25 and age 50 (both collected at age 50)-measured throughout, for consistency, as the registrar general's social class (RGSC) of the head of household using the 1990 classification of occupations collapsed into either manual or non-manual social classes. LLSI, at age 50, was determined using the question: "do you have any long term illness, health problem or handicap which limits your daily activities in any way?"

Cumulative SEP was defined as the number of times, out of three, a person had lived in a manual social class household. Four socioeconomic trajectories (stable nonmanual, upward, downward, and stable manual) over three time phases (birth to age 25, age 25 to age 50, and birth to age 50) were also determined.

Abbreviations: SEP, socioeconomic position; LLSI, limiting longstanding illness; RGSC, registrar general's social class

Table 1 Odds ratios of limiting longstanding illness at age 50 according to cross sectional and life course measures of socioeconomic position

\begin{tabular}{|c|c|c|c|c|c|c|c|c|}
\hline & \multicolumn{4}{|l|}{ Men } & \multicolumn{4}{|c|}{ Women } \\
\hline & $\begin{array}{l}\text { Total } \\
n\end{array}$ & $\begin{array}{l}\text { N (\%) reporting } \\
\text { LLSI }\end{array}$ & $\mathrm{OR}^{*}(95 \% \mathrm{CI})$ & $\chi^{2}$ (p value) & $\begin{array}{l}\text { Total } \\
\mathbf{n}\end{array}$ & $\begin{array}{l}\mathrm{N}(\%) \text { reporting } \\
\text { LLSI }\end{array}$ & OR $(95 \% \mathrm{Cl})$ & $\chi^{2}$ (p value) \\
\hline \multicolumn{9}{|c|}{$\begin{array}{l}\text { Cross sectional SEP, } \\
\text { age } 0\end{array}$} \\
\hline NM & 58 & $6(10.3)$ & 1.00 & & 78 & $12(15.4)$ & 1.00 & \\
\hline$M$ & 176 & $39(22.2)$ & 2.47 (0.98 to 6.23$)$ & $3.90(0.048)$ & 209 & $36(17.2)$ & 1.14 (0.56 to 2.34$)$ & $0.14(0.71)$ \\
\hline \multicolumn{9}{|c|}{$\begin{array}{l}\text { Cross sectional SEP, } \\
\text { age } 25\end{array}$} \\
\hline NM & 98 & $8(8.2)$ & 1.00 & & 137 & 19 (13.9) & 1.00 & \\
\hline$M$ & 126 & $39(31.0)$ & 5.04 (2.15 to 11.81$)$ & $17.19(<0.0001)$ & 137 & 25 (18.3) & 1.39 (0.72 to 2.66$)$ & $0.97(0.32)$ \\
\hline \multicolumn{9}{|c|}{$\begin{array}{l}\text { Cross sectional SEP, } \\
\text { age } 50\end{array}$} \\
\hline NM & 142 & $11(7.8)$ & 1.00 & & 186 & 27 (14.6) & 1.00 & \\
\hline M & 104 & $38(36.5)$ & $6.86(3.12$ to 15.05$)$ & $31.07(<0.0001)$ & 97 & $16(16.5)$ & 1.16 (0.59 to 2.27$)$ & $0.18(0.67)$ \\
\hline \multicolumn{9}{|c|}{$\begin{array}{l}\text { Cumulative SEP } \\
\text { (number of time in } \\
\text { manual RGSC) }\end{array}$} \\
\hline 0 & 39 & $2(5.1)$ & 1.00 & & 44 & $5(11.4)$ & 1.00 & \\
\hline 1 & 52 & $4(7.7)$ & $1.54(0.26$ to 8.99$)$ & & 84 & $12(14.3)$ & $1.30(0.42$ to 3.98$)$ & \\
\hline 2 & 42 & 7 (16.7) & $3.70(0.69,19.79)$ & & 59 & $13(22.0)$ & $2.20(0.71$ to 6.84$)$ & \\
\hline 3 & 69 & $26(37.7)$ & $11.19(2.22$ to 56.37$)$ & $21.90(<0.0001)$ & 56 & $8(14.3)$ & $1.30(0.39$ to 4.32$)$ & $0.50(0.48)$ \\
\hline \multicolumn{9}{|c|}{ SEP trajectory, 0-25 } \\
\hline stable NM & 39 & $2(5.1)$ & 1.00 & & 48 & $5(10.4)$ & 1.00 & \\
\hline upward & 55 & $6(10.9)$ & $2.27(0.42$ to 12.08$)$ & & 83 & $14(16.9)$ & $1.74(0.58$ to 5.23$)$ & \\
\hline downward & 11 & $2(18.2)$ & $4.11(0.48$ to 35.49$)$ & & 19 & $4(21.1)$ & $2.29(0.53$ to 9.93$)$ & \\
\hline stable $M$ & 100 & $30(30.0)$ & 7.93 (1.69 to 37.23$)$ & $11.36(0.0008)$ & 103 & $19(18.5)$ & 1.95 (0.67 to 5.62$)$ & $1.12(0.29)$ \\
\hline \multicolumn{9}{|c|}{$\begin{array}{l}\text { SEP trajectory, } 25- \\
50\end{array}$} \\
\hline stable NM & 87 & $6(6.9)$ & 1.00 & & 121 & $16(13.2)$ & 1.00 & \\
\hline upward & 37 & $4(10.8)$ & $1.64(0.43$ to 6.23$)$ & & 55 & $10(18.2)$ & $1.49(0.61$ to 3.47$)$ & \\
\hline downward & 10 & $2(20.0)$ & $3.38(0.57$ to 20.12$)$ & & 13 & $1(7.7)$ & 0.55 (0.07 to 4.54$)$ & \\
\hline stable $M$ & 85 & $34(40.0)$ & 9.00 (3.24 to 24.96$)$ & $25.07(<0.0001)$ & 74 & $12(16.2)$ & $1.27(0.56$ to 2.87$)$ & $0.60(0.44)$ \\
\hline \multicolumn{9}{|c|}{ SEP trajectory, 0-50 } \\
\hline stable NM & 50 & $2(4.0)$ & 1.00 & & 57 & $6(10.5)$ & 1.00 & \\
\hline upward & 84 & $8(9.5)$ & 2.53 (0.51 to 12.58$)$ & & 116 & $21(18.1)$ & 1.88 (0.71 to 4.99$)$ & \\
\hline downward & 6 & $3(50.0)$ & 24.00 (2.00 to 288.55$)$ & & 16 & $4(25.0)$ & 2.83 (0.67 to 12.01$)$ & \\
\hline stable $M$ & 85 & $28(32.9)$ & 11.79 (2.42 to 57.39 ) & $14.25(0.0002)$ & 70 & $10(14.3)$ & $1.42(0.48$ to 4.19$)$ & $0.30(0.58)$ \\
\hline
\end{tabular}




\section{Key points}

A number of cross sectional and life course measures of socioeconomic position were associated with self reported limiting longstanding illness at age 50 in men. No such associations were apparent in women. This suggests that men carry their experience of socioeconomic deprivation, or affluence, with them, in health terms, throughout their life and are consistent with the accumulative model of socioeconomic variations in health.

Of the 583 male and 559 female babies in the original cohort, data on self reported LLSI and SEP at all three time points were available for $202(34.6 \%)$ men and 243 women $(43.5 \%)$. There was no evidence that this sample differed from the remainder of the original cohort, not included in this study, in terms of SEP at birth $\left(\chi^{2}=0.07, \mathrm{p}=0.79\right)$ but the proportion of women in the sample was greater than in the remainder of the original cohort $\left(\chi^{2}=9.34, p=0.002\right)$. Thirty nine $(19.3 \%)$ men and $38(15.6 \%)$ women reported LLSI. Table 1 shows the odds ratios, with $\chi^{2}$ tests for trendwhere appropriate-of LLSI according to the measures of SEP.

There was evidence of socioeconomic gradients in the presence of LLSI according to all measures of SEP in men with both cross sectional and cumulative experience of manual social classes associated with a greater chance of LLSI. There was also a trend for LLSI to increase according to socioeconomic trajectory from stable non-manual, through upward and downward socioeconomic mobility to stable manual. There was little evidence that any of the measures of SEP were predictive of LLSI in women.

\section{COMMENT}

We have found evidence of a relation between LLSI at age 50 and a number of cross sectional and life course measures of SEP in men, but not in women.

Our results are limited by the small number of people reporting LLSI leading, in some cases, to very wide confidence intervals. A low prevalence of LLSI among a cohort aged only 50 is not unusual and clear trends in the data are present despite this.

It is possible that our failure to find evidence of relations between LLSI and measures of SEP in adult women is attributable to the use of the RGSC of the head of household rather than of individuals themselves. ${ }^{4}$ Previous work that has used life course measures of SEP derived directly from working women has confirmed strong relations with morbidity and mortality. ${ }^{5}$ Alternatively, it is possible that women assess and report their health differently from men.

Our finding that men who are upwardly mobile are healthier than those they leave behind in stable manual

\section{Policy implications}

The effect of social circumstances on health seems to be cumulative throughout the life course. While avoiding deprivation in early life is clearly important, there is evidence that reducing deprivation in adulthood may also have beneficial effects on health.

circumstances, but less healthy than those they join in the non-manual classes who have experienced social stability, and vice versa, suggests that people carry their experience of deprivation, or affluence, with them, in health terms, throughout their life. The results are, therefore, consistent with the accumulative model of socioeconomic variations in health. ${ }^{6}$

\section{ACKNOWLEDGEMENTS}

Many thanks to all participants and staff (both past and present) of the Newcastle thousand families study. The most recent follow up of the Newcastle thousand families study was funded by the Wellcome Trust, the Minnie Henderson Trust, the Sir John Knott Trust, and the Special Trustees of the Newcastle Hospitals. JA is funded by the Faculty of Public Health Medicine/BUPA research fellowship (20014).

\section{Authors' affiliations}

J Adams, M White, School of Population and Health Sciences, The Medical School, University of Newcastle upon Tyne, UK

M S Pearce, L Parker, School of Clinical Medical Sciences, University of Newcastle upon Tyne, Sir James Spence Institute, Royal Victoria Infirmary, Newcastle upon Tyne, UK

Conflicts of interest: none declared.

Correspondence to: Dr J Adams, School of Population and Health Sciences, The Medical School, University of Newcastle upon Tyne NE2 4HH, UK; j.m.adams@ncl.ac.uk

Accepted for publication 23 March 2004

\section{REFERENCES}

1 Davey Smith G, Hart C, Blane D, et al. Lifetime socioeconomic position and mortality: prospective observational study. BMJ 1997;314:547.

2 Hart C, Davey Smith G, Blane D. Social mobility and 21 year mortality in a cohort of Scottish men. Soc Sci Med 1998;47:1121-30.

3 Lamont $D$, Parker $L$, White $M$, et al. Risk of cardiovascular disease measured by carotid intima-media thickness at age 49-51: lifecourse study. BMJ 2000;320:273-8.

4 Carstairs V, Morris R. Deprivation and mortality: an alternative to social class? Community Medicine 1989;11:210-19.

5 Heslop P, Davey Smith G, Macleod J, et al. The socioeconomic position of employed women, risk factors and mortality. Soc Sci Med 2001;53:477-85. 6 Ben-Shlomo Y, Kuh D. A life course approach to chronic disease epidemiology: conceptual models, empirical challenges and interdisciplinary perspectives. Int J Epidemiol 2002;31:285-93. 